\title{
Erythrosis interfollicularis colli and cutis rhomboidalis nuchae: two sides of a coin
}

\author{
Uwe Wollina ${ }^{1 凶}$
}

\begin{abstract}
Introduction: Chronic exposure to sunlight accelerates extrinsic aging due to changes in the extracellular matrix. Cutis rhomboidalis nuchae and erythrosis interfollicularis colli are two benign skin disorders related to extrinsic aging.

Methods: The study investigated possible co-occurrence in 50 male patients that developed skin cancer due to professional outdoor work, and demonstrated cutis rhomboidalis nuchae clinically and by dermoscopy.

Results: The study observed 11 cases of co-existent erythrosis interfollicularis colli characterized by perifollicular white halos in dermoscopy. These patients had Fitzpatrick skin type II or III but not type I. The severity of erythrosis interfollicularis colli was diminished in the area of cutis rhomboidalis nuchae. Basal cell carcinomas were seen in only one patient on the borders of cutis rhomboidalis nuchae, whereas erythrosis interfollicularis colli did not prevent development of basal cell carcinomas. Actinic keratoses were seen in nine of 11 patients with erythrosis interfollicularis colli, but not with cutis rhomboidalis skin.

Conclusions: This study argues for a local protective effect of cutis rhomboidalis nuchae against other ultraviolet light-induced cutaneous pathologies.
\end{abstract}

Keywords: erythrosis interfollicularis colli, cutis rhomboidalis nuchae, dermoscopy, chronic sun exposure, extrinsic aging, basal cell carcinoma, actinic keratosis

Received: 8 November 2018 | Returned for modification: 30 November 2018 | Accepted: 30 November 2018

\section{Introduction}

Erythrosis interfollicularis colli was first described by Leder in 1944 (1). It is a frequent but usually asymptomatic condition of adult middle-aged and elderly Caucasians. A triangular and rhomboid median zone (décolleté, lateral, and dorsal neck) with an appearance of "plucked chicken skin" is clinically characteristic. The submental and retroauricular skin remain unaffected. Histologically, there are dilatation of sebaceous glands, elastic tissue alterations, and telangiectasias (2). From histological studies of aging skin, it is known that the thinnest superficial dermal collagen fibers undergo fragmentation and finally lysis, a process that starts around the age of 50. The thinning of the superficial dermis is due to the quantitative reduction of collagen fibers. This is accompanied by fragmentation of elastic fibers. They gradually change their tinctorial affinity and become reduced quantitatively (3). Neutrophils infiltrate sun-exposed skin. Matrix metalloproteinases become activated through the release of neutrophil elastase, contributing to extracellular matrix damage seen in solar elastosis (4).

Cutis rhomboidalis nuchae is a characteristic disorder related to chronic sun exposure during outdoor work. The skin acquires a leathery aspect, with a yellowish and grooved surface. Solar elastosis with degeneration of elastic and collagen fibers is found in the dermis (5). Data on the prevalence and incidence of the disease are scant. The Cooperative Health Research in the Augsburg Region (KORA) in southern Germany, a population-based survey of the adult population, reported cutis rhomboidalis nuchae in $18.3 \%$ of the population (6). Recently, it has been suggested that cutis rhomboidalis nuchae may protect against non-melanoma skin cancer $(7,8)$. This study investigated the coexistence of both benign conditions in males with a long-term history of outdoor work and ultraviolet (UV)-induced skin cancer.

\section{Methods}

In Germany, skin cancer (multiple actinic keratoses and cutaneous squamous cell carcinoma) from chronic sun exposure due to outdoor work is a recognized occupational skin disease after confirmation of diagnosis and an occupational UV exposure of more than $40 \%$ of lifetime UV exposure (9). The author runs a specialized outpatient clinic for these patients.

Consecutive adult patients with skin cancer-squamous cell carcinoma and/or multiple actinic keratoses (field cancerization)-related to outdoor professions in patients attending the outpatient clinic for assessment were examined for clinical symptoms (Table 1).

Patients with a current medication with possible photosensitive drugs were excluded. All patients had an occupational UV exposure of more than $40 \%$ of lifetime UV exposure.

All the patients were Caucasians with Fitzpatrick skin types I to III. They were investigated for cutis rhomboidalis nuchae. They werealso investigated for the presence of erythrosisinterfollicularis

Table 1 | Patient characteristics.

\begin{tabular}{lc}
\hline Variable & $n(\%)$ \\
\hline Professions & $36(72)$ \\
$\quad$ Construction workers & $6(12)$ \\
Roofers & $5(10)$ \\
$\quad$ Farmers, gardeners & $3(6)$ \\
$\quad$ Others (surveyor, policeman, painter) & $6(12)$ \\
Education and/or training on sun safety & $44(88)$ \\
Regular protective headgear at work & \\
Regular protective clothing at work & $48(96)$ \\
$\quad$ Long pants & $37(74)$ \\
$\quad$ Long-sleeved shirts & $7(14)$ \\
Regular use of sunscreens at work & $3(6)$ \\
Frequent use of fragrances in the area of erythrosis & \\
interfollicularis colli &
\end{tabular}

Dresden Municipal Hospital, Dresden Academic Teaching Hospital, Dresden, Germany.凶Corresponding author: uwollina@gmail.com; wollina-uw@ khdf.de 
colli and current skin cancer. The examination was performed clinically and using dermoscopy. Dermoscopic examination was performed using a DermLite camera with polarized light (10x magnification; 3 Gen, Dana Point, CA). The DermLite camera contains polarization filters, and therefore immersion liquids do not need to be applied during skin examination.

The relative risk of cancer development was calculated for lesional skin of cutis rhomboidalis and erythrosis interfollicularis colli. Relative risk was calculated by dividing the probability of an event (skin cancer) occurring for group A with erythrosis interfollicularis divided by the probability of an event occurring for group B with cutis rhomboidalis. It is a descriptive statistic. Due to the limited number of patients, no other descriptive statistic was used.

\section{Results}

The study examined 50 males between ages 58 and 76 (mean age $68.5 \pm 7.2$ years). All were Caucasians with Fitzpatrick skin types I to III. Professions and the mode of photoprotection used at work are summarized in Table 1.

Erythrosis interfollicularis colli was not observed in five patients with Fitzpatrick skin type I, but it was observed in 11 of 45 patients with Fitzpatrick skin type II or III. All affected patients presented with a triangular and rhomboid distribution of the erythematous area (Fig. 1). Dermoscopy revealed a combination of linear vascular reddish structure and perifollicular white halos measuring 0.5 to $1.2 \mathrm{~mm}$ (Fig. 2).

The area affected by cutis rhomboidalis nuchae presented erythrosis interfollicularis colli to a milder degree (Fig. 3). However, there was no association with the severity and depth of the wrinkles.

Twenty-one of the 50 patients presented with a current basal cell carcinoma of the neck and upper trunk, and 35 suffered from actinic keratoses. None had a current squamous cell carcinoma. Basal cell carcinomas were observed in six patients within the area of erythrosis interfollicularis colli, but only one tumor was localized in the area of cutis rhomboidalis nuchae. Areas affected by erythrosis interfollicularis colli exhibited a 5.88-times greater relative risk for basal cell carcinomas compared to cutis rhomboidalis nuchae. Actinic keratoses were not observed in cutis rhomboidalis skin, but they were observed in three of the $11(27.3 \%)$ patients within erythrosis interfollicularis colli.

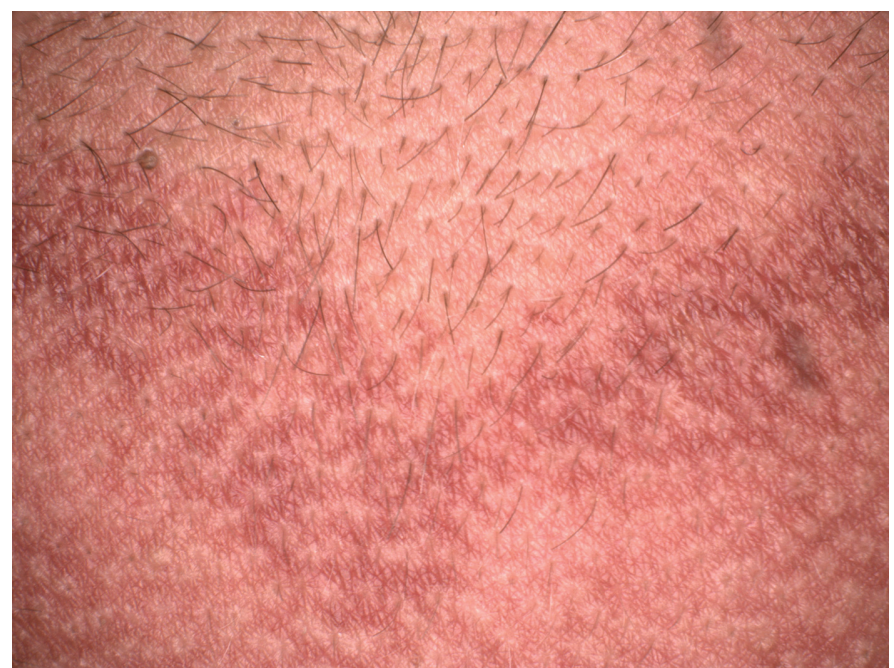

Figure 1 | Clinical appearance of erythrosis interfollicularis colli in a 62-yearold male.

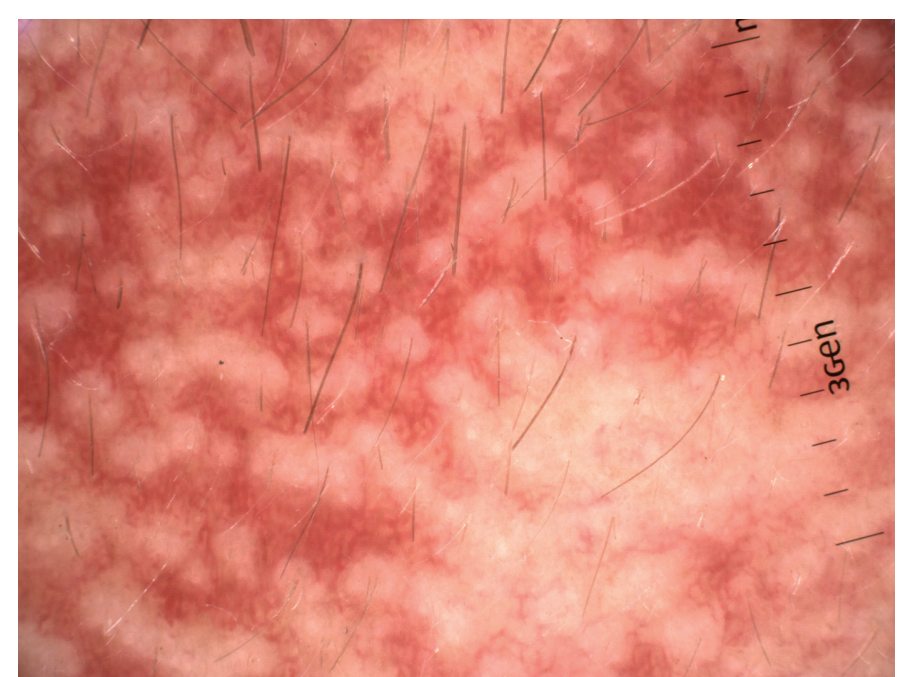

Figure 2 | Dermoscopy of erythrosis interfollicularis colli, demonstrating a network of enlarged cutaneous vessels and perifollicular white halos in a 62-yearold male.

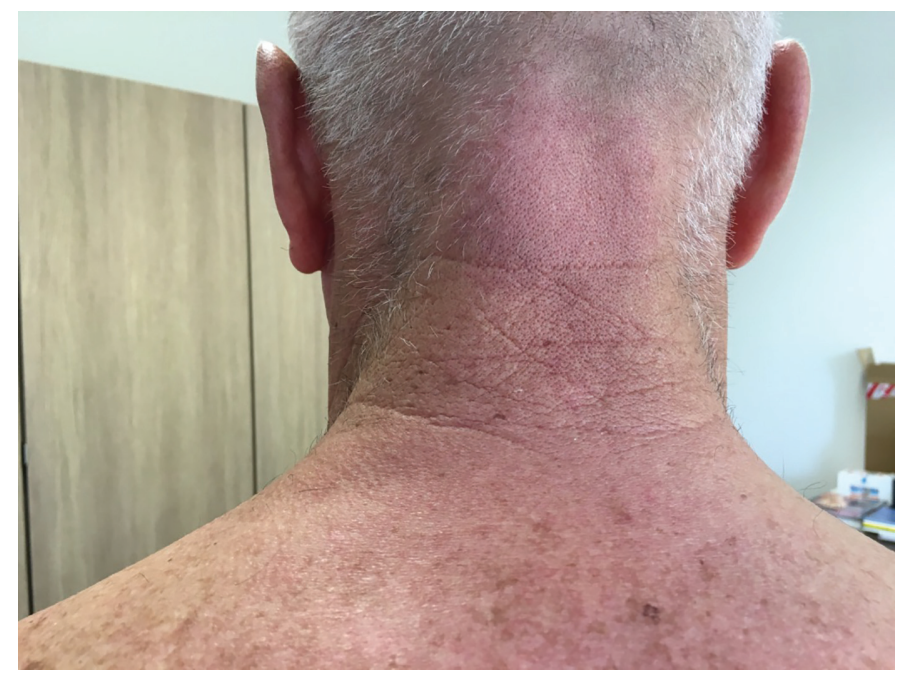

Figure 3 | Cutis rhomboidalis nuchae with erythrosis interfollicularis colli in a 74-year-old male with Fitzpatrick skin type II.

\section{Discussion}

Erythrosis interfollicularis colli and cutis rhomboidalis nuchae are two skin diseases associated with chronic exposure to sunlight and are more frequent with increasing age. Both are asymptomatic and probably underdiagnosed. Because extrinsic aging due to natural UV light irradiation is a co-factor of skin cancer development-in particular non-melanoma skin cancer (NMSC)the study also investigated the occurrence of NMSC with cutis rhomboidalis nuchae and erythrosis interfollicularis colli.

Erythrosis interfollicularis colli has a peculiar dermoscopic finding: the perifollicular white halo, or a well-defined, round, homogeneous whitish area surrounding the follicular opening of the hair follicle (the "full-moon sign"; Fig. 2). Although it is not specific, it is characteristic for the disease (10). A grayish-white halo has been described in central centrifugal cicatricial alopecia (11). "White dots" have been reported in lichen planopilaris (12).

The "full-moon sign" can be explained by the three-dimensional microvasculature network around the hair follicle, which is most dense at its bottom and becomes sparse in its upper part. This is altered by chronic sun exposure, leading to fibrosis (13).

The disease is caused by intense sun exposure and is probably worsened by photosensitive ingredients of fragrances used 
by patients (2). In this study's cohort, fragrances were of minor importance. The changes are irreversible. Patients with a highly photosensitive skin type often avoid direct sun exposure and protect their skin more regularly. This could explain why no erythrosis interfollicularis colli was observed in patients with Fitzpatrick skin type I.

Cutis rhomboidalis nuchae is a particular type of solar elastosis of the dorsal neck with thickening of the epidermis (14). It has gained importance as a clinical sign of chronic sun exposure in outdoor workers (8). The "full moon sign" is missing. Increased epidermal and stratum corneum thickness is a cutaneous response to UV light irradiation that increases the minimal erythema dose fourfold to fivefold. This may be the major local protective factor in cutis rhomboidalis nuchae. Together with skin pigmentation, the minimal erythema dose can be increased up to 40-fold $(15,16)$.

The distribution of basal cell carcinomas and actinic keratoses of the neck and upper trunk argued for a local skin cancer pro- tective effect of cutis rhomboidalis nuchae but not of erythrosis interfollicularis colli $(7,8)$.

The study demonstrated that non-malignant disorders due to chronic sun exposure have a different potential for intrinsic cancer development. Sun protection in outdoor professions should become part of education. Protective clothing and sunscreens are tools for decreasing the risk of skin cancer development in outdoor workers (17).

\section{Conclusions}

This study highlights the different pathogenesis of the two disorders caused by chronic sun exposure and the diagnostic relevance of dermoscopy, and it supports the concept that cutis rhomboidalis has a local protective effect on other skin diseases induced by chronic sun exposure, such as basal cell carcinoma or actinic keratosis $(7,8)$.

\section{References}

1. Leder M. Erythrosis interfollicularis colli. Dermatology. 1944;89:132-8.

2. Colomb D, Racouchot J, Gho A, Vernet G. L'erythrosis inter-follicularis colli de Leder. Ann Dermatol Vénéréol. 1977;104:238-42. French.

3. Bonta M, Daina L, Muţiu G. The process of ageing reflected by histological changes in the skin. Rom J Morphol Embryol. 2013;54:797-804.

4. Takeuchi H, Gomi T, Shishido M, Watanabe H, Suenobu N. Neutrophil elastase contributes to extracellular matrix damage induced by chronic low-dose UV irradiation in a hairless mouse photoaging model. J Dermatol Sci. 2010;60:151-8.

5. Tosti A. Cutis rhomboidalis nuchae. Rass Dermatol Sifilogr. 1953;6:175-204.

6. Schäfer T, Merkl J, Klemm E, Wichmann HE, Ring J; KORA Study Group. The epidemiology of nevi and signs of skin aging in the adult general population: Results of the KORA-survey 2000. J Invest Dermatol. 2006;126:1490-6.

7. Bonkevitch F, Souza PR. Cutis rhomboidalis protects skin from malignant epithelial tumors. Med Hypotheses. 2014;82:652-3.

8. Wollina U. Cutis rhomboidalis nuchae und beruflicher UV-bedingter Hautkrebs. Dermatol Beruf Umwelt. 2015;63:137-40. German.

9. Diepgen TL, Bernhardt-Klimt C, Blome O, Brandenburg S, Dienstbach D, Drexler $\mathrm{H}$, et al. Bamberger Merkblatt: Begutachtungsempfehlungen für die Begutachtung von Haut- und Hautkrebserkrankungen. Teil II: Hautkrebserkrankungen. Dermatol Beruf Umwelt. 2009;57:3-17. German.

10. Vazquez-Lopez F, Mas-Vidal A, Sanchez-Martin J, Pérez-Oliva N, Argenziano G. Perifollicular white halo: a dermoscopic subpattern of melanocytic and nonmelanocytic skin lesions. Arch Dermatol. 2009;145:1350.

11. Miteva M, Tosti A. Dermoscopy guided scalp biopsy in cicatricial alopecia. J Eur Acad Dermatol Venereol. 2013;27:1299-303.

12. Rudnicka L, Olszewska M, Rakowska A, Slowinska M. Trichoscopy update 2011. J Dermatol Case Rep. 2011;5:82-8.

13. Sakita S, Ohtani O, Nakatani T, Morohashi M. Three-dimensional microvasculature of the hair follicle. J Dermatol Sci. 1994;7:S1-4.

14. Watson REB, Gibbs NK, Griffiths CEM, Sherratt MJ. Damage to skin extracellular matrix induced by UV exposure. Antioxid Redox Signal. 2014;21:1063-77.

15. Koehler M), Kellner K, Hipler UC, Kaatz M. Acute UVB-induced epidermal changes assessed by multiphoton laser tomography. Skin Res Technol. 2015;21:137-43.

16. Lavker RM, Gerberick GF, Veres D, Irwin CJ, Kaidbey KH. Cumulative effects from repeated exposures to suberythemal doses of UVB and UVA in human skin. J Am Acad Dermatol. 1995;32:53-62.

17. Rocholl M, Ludewig M, Skudlik C, Wilke A. Occupational skin cancer: prevention and recommendations for UV protection as part of the treatment approved by the public statutory employers' liability insurance. Hautarzt. 2018;69:462-70. German. 